\title{
Improvement the InAs, InSb, GaAs and GaSb surface state by nanoscale wet etching
}

\author{
Iryna Levchenko ${ }^{1,2}\left(\right.$ Vasyl Tomashyk $^{1} \cdot$ Galyna Malanych $^{1} \cdot$ Iryna Stratiychuk $^{1} \cdot$ Andrii Korchovyi $^{1}$
}

Received: 2 January 2021 / Accepted: 5 March 2021 / Published online: 1 April 2021

(c) The Author(s) 2021

\begin{abstract}
Various experimental approaches of the wet nanoscale treatment have been proposed to account for features of the InAs, $\mathrm{InSb}$ and $\mathrm{GaAs}, \mathrm{GaSb}$ semiconductor dissolution process in the $\left(\mathrm{NH}_{4}\right)_{2} \mathrm{Cr}_{2} \mathrm{O}_{7}-\mathrm{HBr}-\mathrm{EG}$ etching solution. Etching kinetics data showed that a crystal dissolution has diffusion-determined nature. The lowering of the solvent concentration from 80 to 0 vol.\% in the solution was accompanied by a significant increase in the semiconductor etching speed. Depending on the solution composition, we have studied two types of crystal surface morphology, polished and passivated by the film, which was formed after chemical-dynamic (CDP) and/or chemical-mechanic polishing (CMP) in the solution, saturated by solvent and by oxidant, accordingly. It was found that in the polished etchants both CDP and CMP procedures lead to the formation of the mirror-like and super-smooth surface with nanoscale roughness less than $1 \mathrm{~nm}$. The obtained results of surface state indicate that the $\left(\mathrm{NH}_{4}\right)_{2} \mathrm{Cr}_{2} \mathrm{O}_{7}-\mathrm{HBr}-\mathrm{EG}$ etchants could be used successfully for controllable CDP and CMP treatment of III-V semiconductors and formation of super-smooth surface.
\end{abstract}

Keywords Semiconductor $\cdot$ Bromine-emerging etchant $\cdot$ Polishing solution $\cdot$ Surface $\cdot$ Diffusion

\begin{tabular}{ll}
\multicolumn{2}{l}{ Abbreviations } \\
CDP & Chemical-dynamic polishing \\
CMP & Chemical-mechanical polishing \\
EG & Ethylene glycol \\
AFM & Atomic force microscopy \\
EDS/EDX & Energy dispersive X-ray spectroscopy
\end{tabular}

\section{Introduction}

III-V semiconductors are widely used in the manufacturing of gas detection systems, photodetectors, optogenetics, biomedical applications, high electron mobility and heterojunction bipolar transistors, resonant tunneling diodes, spintronic devices solar cells, optical windows (Kimukin et al. 2003; Bennett et al. 2005).

The investigation of the etching nature and features of the treated crystal plays a crucial role for the development of

Iryna Levchenko

levchenko@unipress.waw.pl

1 V. Lashkaryov Institute of Semiconductor Physics, National Academy of Science of Ukraine, Kyiv, Ukraine

2 Institute of High Pressure Physics (Unipress), Polish Academy of Science, Warsaw, Poland the nano-size surface structure and materials science. Surface defects are exceedingly detrimental for the efficiency of devices. Top layers contain dangling bonds, structure inhomogeneities and impurities. These defects cause the generation of leaky paths for carriers and non-radiative recombination (Seong and Amano 2020). For the nanoscale control of surface morphology and composition, it is extremely required to understand the nature of the semiconductor dissolution.

Among a host of possible semiconductor polishing techniques, for instance dry, plasma and wet etchings, the last one is the most popular procedure to obtain the polished substrate surface. Crystal dissolution in liquid etchants helps to avoid the crystallographic damages during cleaning process, in comparison with dry methods. Also, having an isotropic nature the wet processing promotes similar dissolution rate in all directions (Xie 2005).

However, understanding the limitation of the procedures type on the dissolution process and surface characteristic is not clear due to technical constraints, such as different type of etching equipment and process condition, method of the activation energy measurement, possibility to estimate the amount of all reagents before and after dissolution, availability of the effective post-treatment procedure, etc. 
The selective etching process of GaAs substrates was performed in the dynamic regime at $200 \mathrm{rpm}$, using $\mathrm{C}_{6} \mathrm{H}_{8} \mathrm{O}_{7}-\mathrm{H}_{2} \mathrm{O}_{2}$ (4:1) solution. The etch rate was $0.4 \mu \mathrm{m} / \mathrm{min}$ at room temperature (Kuźmicz et al. 2017). After comparison of the influence of $\mathrm{C}_{6} \mathrm{H}_{8} \mathrm{O}_{7}-\mathrm{H}_{2} \mathrm{O}_{2}$ and $\mathrm{NH}_{4} \mathrm{OH}-\mathrm{H}_{2} \mathrm{O}_{2}$ solutions on the wafer, it was reported that the $\mathrm{GaAs}$ and $\mathrm{GaSb}$ dissolution rate in the basic etchant is faster than in the acidic solution. Dissolution speed varies with process time owing to the degradation of solution composition (Renteria et al. 2015).

$\mathrm{C}_{6} \mathrm{H}_{8} \mathrm{O}_{7}$ (citric acid) and $\mathrm{C}_{4} \mathrm{H}_{6} \mathrm{O}_{6}$ (tartaric acid) were used as the solvent of $\mathrm{GaSb}$ oxidation products (Kowalewski et al. 2016). Citric acid increases the dissolution rate and reduces the surface roughness. It needs to note that the temperature increase provides the evolution of reaction products (gas bubbles) on the surface during the dissolution process. Procedure of etchant stirring helps to uniform remove of the etching products.

$\mathrm{H}_{3} \mathrm{PO}_{4} / \mathrm{H}_{2} \mathrm{O}_{2} / \mathrm{H}_{2} \mathrm{O} / \mathrm{C}_{6} \mathrm{H}_{8} \mathrm{O}_{7}$ etching solutions with 10-40 $\mathrm{ml} \mathrm{H}_{2} \mathrm{O}_{2}$ produce mirror-like surface of InAs and GaSb semiconductors (Hong-Yue et al. 2015). When the oxidant $\left(\mathrm{H}_{2} \mathrm{O}_{2}\right)$ reaches a threshold concentration value, it cannot result in growing of the crystal dissolution rate due to the passivation of wafer. Reaching the etchant composition by the $\mathrm{H}_{3} \mathrm{PO}_{4}$ and citric acid promotes the increase in dissolution rate. $\mathrm{GaSb}$ wafers contribute concentrated etching solution (more saturated by $\mathrm{C}_{6} \mathrm{H}_{8} \mathrm{O}_{7}$ ), in comparison with InAs substrates. The last one achieves the similar etching rate at the minimum volume of citric acid. Such tendency can be explained by bigger bonding energy of $\mathrm{GaSb}$ in comparison with InAs (Tripathy and Pattanaik 2016).

To obtain the active surface of gallium arsenide, three process stages were proposed: non-selective etching, $\left(\mathrm{H}_{2} \mathrm{O}_{2}-\mathrm{H}_{2} \mathrm{O}-\mathrm{NH}_{4} \mathrm{OH}\right)$, selective etching $\left(\mathrm{H}_{2} \mathrm{O}_{2}-\mathrm{NH}_{4} \mathrm{OH}\right)$ and the substrate selective etching $\left(\mathrm{H}_{2} \mathrm{O}_{2}-\mathrm{NaOH}\right)$ (Qiu et al. 2016). The chemical treatment by aqueous solution of $0.04 \%$ $\mathrm{HF}-0.45 \% \mathrm{C}_{3} \mathrm{H}_{6} \mathrm{O}_{3}-0.09 \% \mathrm{H}_{2} \mathrm{O}_{2}$ produced the remove of $150 \mathrm{~nm}$ of InSb surface after $20 \mathrm{~s}$ of the reaction time (Masuda et al. 2018).

InAs wafers were used to expound oxidation and etching behaviors of the crystal surface with acidic- and basic- $\mathrm{H}_{2} \mathrm{O}_{2}$ etchants ( $\mathrm{Na}$ et al. 2017). It was noted that the high oxidizing nature of $\mathrm{H}_{2} \mathrm{O}_{2}$ in the solutions determines the dissolution speed. Etching compositions promote the formation of oxides and hydroxides on the treated surface witch could be clarified by various oxidation states depending on the solution. After research of the solution composition impact on the surface state, it was concluded that acidic etchants are more perspective for InAs wafer treatment.

Acidic etching mixture, based on $\mathrm{HCl}-\mathrm{H}_{2} \mathrm{O}$ composition, was used for the native oxide remove from the $\mathrm{GaSb}$ wafer (Hospodkova et al. 2017). The etching impact of HClbased composition on the GaSb substrates was described in
You et al. (2017). According to different nature of oxidant, the $\mathrm{GaSb}$ dissolution rate changes in the range from 40 to $4 \times 10^{3} \mathrm{~nm} / \mathrm{min}$, and the surface is smooth or mirror with roughness $1.7-3 \mathrm{~nm}$.

Behaviors of the GaSb and InSb wafers cleaning in acidic and basic etchant composition based on $\mathrm{H}_{2} \mathrm{O}_{2}$ were studied in Seo et al. (2017). The key role in the oxidation process of crystal has $\mathrm{H}_{2} \mathrm{O}_{2}$. It was reported that the oxidation reaction on the gallium antimonide surface in $\mathrm{H}^{+}$-solution retards with the dilution. In the $\mathrm{HO}^{-}$-solution, the oxidation reaction accelerates with the dilution. The wafer treatment by acidic solution promotes hydrophilic features of surface. The overall reaction rate determines by the competition of wafer oxidation and oxide etching. The group III elements behaviors play the main role in the determination of surface features.

Antimonides contribute the strong oxidizing agent $\left(\mathrm{H}_{2} \mathrm{O}_{2}\right.$, $\mathrm{HNO}_{3}$ ) to dissolve the partially soluble compounds of $\mathrm{Sb}$. Based on these oxidants, compositions led to the degradation of the results reproducibility and the possibility to control etching process (Vanýsek 2020). The bromine-emerging mixtures contain the less-aggressive oxidant and are characterized by slow dissolution rate of III-V semiconductors (Levchenko et al. 2017a, b). This behavior helps to decline the possibility of bubble generation, in comparison with $\mathrm{H}_{2} \mathrm{O}_{2}$-based solution, which can produce the formation of etching pit. In addition, $\left(\mathrm{NH}_{4}\right)_{2} \mathrm{Cr}_{2} \mathrm{O}_{7}-\mathrm{HBr}$-solvent composition provides the slow and controllable dissolution of semiconductor and the bromides, as reaction products, promote the transition of dissolution process into diffusion region. We assume that $\left(\mathrm{NH}_{4}\right)_{2} \mathrm{Cr}_{2} \mathrm{O}_{7}$-based etchants are more perspective for CDP and CMP treatment of InAs, InSb, GaAs and $\mathrm{GaSb}$ semiconductors.

\section{Experimental and methods}

In this paper, we compare various types of wet-chemical processing and their affect on the surface characteristic. Dissolution model was studied using aqueous etchants based on $\left(\mathrm{NH}_{4}\right)_{2} \mathrm{Cr}_{2} \mathrm{O}_{7}$ and $\mathrm{HBr}$. Wet-chemical cleaning includes etching (semiconductor dissolution after crystal interaction with etchant components) and polishing/smoothing.

Treatment process was conducted in order to investigate the polishing method influence on features of crystal dissolution and the surface state quality.

The comparison of the InAs, InSb, GaAs, and GaSb crystals surface, untreated and etched by CDP and CMP process in the $\left(\mathrm{NH}_{4}\right)_{2} \mathrm{Cr}_{2} \mathrm{O}_{7}-\mathrm{HBr}$-EG-etching solution has been described for the first time in this work. We have established the effect of the hydrodynamic condition and mechanical impact on the dissolution process and the surface state. Bromine-emerging etching solutions based on $\left(\mathrm{NH}_{4}\right)_{2} \mathrm{Cr}_{2} \mathrm{O}_{7}$ were developed in our department, in the $\mathrm{V}$. 
Lashkaryov Institute of Semiconductor Physics of NAS of Ukraine (Kyiv) (Levchenko et al. 2017a, b).

III-V semiconductor wafers of $25 \mathrm{~mm}^{2}$ in size were pre-cleaned before etching. Then, samples were polished utilizing CDP or CMP process with follow rinsing in $\mathrm{Na}_{2} \mathrm{~S}_{2} \mathrm{O}_{3} \rightarrow \mathrm{H}_{2} \mathrm{O} \rightarrow \mathrm{NaOH} \rightarrow \mathrm{H}_{2} \mathrm{O}$ to remove contaminants. $\mathrm{CDP}$ was carried out in reproducible hydrodynamic conditions. Technique bases on the method of disc rotating (Perevoshchikov 1995). It promotes the laminar movement of etchant over the substrate surface and the removing of damaged layers.

CMP procedure was performed by the non-abrasive etching solution to avoid the rough effect of abrasive particles on the surface quality. For this operation, we used a special etching polisher, covered by a cambric tissue.

As initial components of the etchant mixture we have employed aqueous solutions, which are comprised of: 26 mass.\% $\left(\mathrm{NH}_{4}\right)_{2} \mathrm{Cr}_{2} \mathrm{O}_{7}$ (reagent grade), 42 mass.\% $\mathrm{HBr}$ (extrapure grade) and $\mathrm{CH}_{2}(\mathrm{OH}) \mathrm{CH}_{2}(\mathrm{OH})$ (ethylene glycol, EG, reagent grade).

Using methods of the Scheffe's Simplex lattice theory and the mathematic planning on simplex, we optimized a number of experiments and mixture design (Arimanwa et al. 2019). In the case of CDP process, the concentration interval of etchant composition contains 2-22 vol.\% of $\left(\mathrm{NH}_{4}\right)_{2} \mathrm{Cr}_{2} \mathrm{O}_{7}$, $\mathrm{HBr}$ within 2-98 vol.\% and 0-80 vol.\% of EG was investigated. For CMP process, we applied the initial solution (in vol.\%): $11\left(\mathrm{NH}_{4}\right)_{2} \mathrm{Cr}_{2} \mathrm{O}_{7}-49 \mathrm{HBr}-40 \mathrm{EG}$.

The three-component model is represented by the fourthdegree simplex lattice equation:

$$
\begin{aligned}
y= & k_{1} x_{1}+k_{2} x_{2}+k_{3} x_{3}+k_{4} x_{1} x_{2}+k_{5} x_{1} x_{3}+k_{6} x_{2} x_{3} \\
& +k_{7} x_{1} x_{2}\left(x_{1}-x_{2}\right)+k_{8} x_{1} x_{3}\left(x_{1}-x_{3}\right)+k_{9} x_{2} x_{3}\left(x_{2}-x_{3}\right) \\
& +k_{10}\left(x_{1}-x_{2}\right)^{2} x_{1} x_{2}+k_{11}\left(x_{1}-x_{3}\right)^{2} x_{1} x_{3}+k_{12}\left(x_{2}-x_{3}\right)^{2} x_{2} x_{3} \\
& +k_{13} x_{1}^{2} x_{2} x_{3}+k_{14} x_{1} x_{2}^{2} x_{3}+k_{15} x_{1} x_{2} x_{3}^{2}
\end{aligned}
$$

where $y$-etching rate, $X_{1}, X_{2}, X_{3}$-the concentration of etchant components in the solution $\left(\left(\mathrm{NH}_{4}\right)_{2} \mathrm{Cr}_{2} \mathrm{O}_{7}, \mathrm{HBr}\right.$ and $\mathrm{EG}$, accordingly), $k_{1} \ldots k_{15}$-parameters of the model (Cornell 1986).

The dependence of the etch rate on the modifier concentration was considered for the range $0-95$ vol.\% $\mathrm{CH}_{2}(\mathrm{OH})$ $\mathrm{CH}_{2}(\mathrm{OH})$.

Etch rate was estimated by the electronic indicator TESA DIGICO 400 with accuracy of $0.02 \mu \mathrm{m}$. For precision calculation of the crystal dissolution rate, the process time was extended according to the decrease in etching speed. The atomic force microscopy (AFM) data of the surface morphology were obtained in periodic contact mode on the air, using the microscope NanoScope IIIa Dimension 3000 ${ }^{\mathrm{TM}}$ (Digital Instruments, USA).
Raman scattering analysis were carried out at $293 \mathrm{~K}$ in the quasi-backscattering geometry with a Horiba Jobin Yvon T64000 triple spectrometer. An edge filter was placed in front of the spectrometer entrance to remove the elastically dispersed light, and an $\mathrm{Ar}^{+}$-ion laser with line at $488.0 \mathrm{~nm}$ was used for the excitation. An Olympus BX41 microscope equipped with a 50× objective (Numerical Aperture NA $=0.90$ ) was used to focus the laser light on the sample to a spot size of $\sim 1 \mu \mathrm{m}$. The laser power, which was exposed on the sample surface, was always kept below $3 \mathrm{~mW}$, in order to obtain an acceptable signal-to-noise ratio and to prevent laser heating. The spectral resolution was approximately $0.2 \mathrm{~cm}^{-1}$. Correct instrument calibration was verified by checking the position of the emitting line of Ne lamp at $540.056 \mathrm{~nm}$.

The surface composition analysis was performed by energy dispersive spectroscopy (EDS/EDX) on a Zeiss EVO 50XVP with INCAPentaFETx 3 energy dispersive X-ray spectrometer system for elemental analysis with an accuracy of $\sim 0.1 \%$. Images of the wafer surfaces were obtained at accelerating voltages $V=7-26 \mathrm{kV}$, a probe current $I=40 \mathrm{pA}$, and magnifications from $5 \times$ to $1,000,000 \times$.

\section{Results and discussion}

Etching process of semiconductors is followed by redox reactions due to the etchant molecules interaction with crystals. The etching rate of III-V semiconductors dissolution in the binary and $\left(\mathrm{NH}_{4}\right)_{2} \mathrm{Cr}_{2} \mathrm{O}_{7}-\mathrm{HBr}-\mathrm{EG}$ compositions demonstrates the linear dependency on the solvent concentration in all concentration range. The investigated concentration interval is characterized by the $0.1-8.4 \mu \mathrm{m} / \mathrm{min}$ etch rate (Levchenko et al. 2017a, b). The reactive feature of wafers was evident at the maximum concentrations of oxidant. Crystals become more stable in the systems with minimum of $\mathrm{Cr}_{2} \mathrm{O}_{7}{ }^{2-}$ ions as supported by the lowest etching rate.

The mixture design model for the investigated three-component system is described as:

$$
\begin{aligned}
y= & 2 x_{1}+1,5 x_{2}+0,1 x_{3}+19,8 x_{1} x_{2}+2,6 x_{1} x_{3}+2,4 x_{2} x_{3} \\
& +12,5 x_{1} x_{2}\left(x_{1}-x_{2}\right)+2,4 x_{1} x_{3}\left(x_{1}-x_{3}\right)+4,3 x_{2} x_{3}\left(x_{2}-x_{3}\right) \\
& +24,3\left(x_{1}-x_{2}\right)^{2} x_{1} x_{2}-9,3\left(x_{1}-x_{3}\right)^{2} x_{1} x_{3}-4,3\left(x_{2}-x_{3}\right)^{2} x_{2} x_{3} \\
& +73,1 x_{1}^{2} x_{2} x_{3}-103,2 x_{1} x_{2}^{2} x_{3}-8,8 x_{1} x_{2} x_{3}^{2}
\end{aligned}
$$

The crystal etching kinetic has diffusion-controlled nature, because of the insignificant temperature coefficient and apparent activation energy as low as $35 \mathrm{~kJ} / \mathrm{mol}$. Etching rate was found to be dependent on solution rotation rate, in contrast to the temperature variation. Dissolution is determined by speed of the diffusion on crystal/solution interface. 
Rotation rate-dependent measurement showed that the hydrodynamics of the nanoscale etching system is important for variating the processing features.

In the basic solution, the replacement of polishing process type from CDP to CMP promotes the increase in dissolution rate from $1.5-2.1$ to $37-57 \mu \mathrm{m} / \mathrm{min}$. It could be explained by mechanical influence of CMP operation (Levchenko et al. 2018).

Nanoscale etching provides the extensive dissolution rate data for a wide range of ethylene glycol. Crystals are more stable in EG-rich mixture as supported by the minimum value $(0.1 \mu \mathrm{m} / \mathrm{min}$ and $1 \mu \mathrm{m} / \mathrm{min})$ of the etch rate.

Dissolution rate decreases to with increase in EG concentration in both cases of CDP and CMP procedure, respectively.

Composition with maximum value of $\left(\mathrm{NH}_{4}\right)_{2} \mathrm{Cr}_{2} \mathrm{O}_{7}$ provides the different quality of substrate polished surface. In the case of $\mathrm{A}^{\mathrm{III}} \mathrm{Sb}$ substrate, etchants are characterized by the weak polishing features. After CDP, the surface of antimonides was passivated by white film. This effect is followed by the decrease in the reaction speed.

Figure 1 presents the difference between polished surface and the surface covered with thin film.

Film passivation of $\mathrm{InSb}$ in the non-polishing mixture prevents from the fresh etchant reaching onto the surface. Thus, the semiconductor dissolution is not uniform over the whole crystal area and the surface roughness does not change significantly.

The polishing compositions resulted in the mirror-like substrate surface in the both case of CDP and CMP procedures. According to the AFM data, the substrate dissolution in the binary etchant system triggers the less intensive decline of the roughness, independently from cleaning procedure (Table 1).

The presence of single generations indicates about the etching of crystal defect, which could be formed during the growing or cutting operation (Fig. 2).

Summarizing obtained results, we are forced to conclude that CPM treatment produces the more homogeneous surface (with less roughness), in comparison with CDP. However,
Table 1 Influence of etchant composition and processing type on the roughness parameter $\left(R_{a}\right)$ of InSb and InAs semiconductors

\begin{tabular}{llll}
\hline Material & Treatment & Etchant composition & $\begin{array}{l}\text { Rough- } \\
\text { ness, } R_{a} \\
(\mathrm{~nm})\end{array}$ \\
\hline InAs & $\mathrm{CMP}$ & $\left(\mathrm{NH}_{4}\right)_{2} \mathrm{Cr}_{2} \mathrm{O}_{7}-\mathrm{HBr}-\mathrm{EG}$ & 0.2 \\
$\mathrm{InSb}$ & $\mathrm{CMP}$ & $\left(\mathrm{NH}_{4}\right)_{2} \mathrm{Cr}_{2} \mathrm{O}_{7}-\mathrm{HBr}-\mathrm{EG}$ & 0.3 \\
$\mathrm{InAs}$ & $\mathrm{CMP}+\mathrm{CDP}$ & $\left(\mathrm{NH}_{4}\right)_{2} \mathrm{Cr}_{2} \mathrm{O}_{7}-\mathrm{HBr}$ & 3.2 \\
InSb & $\mathrm{CMP}+\mathrm{CDP}$ & $\left(\mathrm{NH}_{4}\right)_{2} \mathrm{Cr}_{2} \mathrm{O}_{7}-\mathrm{HBr}$ & 1.1 \\
InAs & $\mathrm{CMP}+\mathrm{CDP}$ & $\left(\mathrm{NH}_{4}\right)_{2} \mathrm{Cr}_{2} \mathrm{O}_{7}-\mathrm{HBr}-\mathrm{EG}$ & 0.3 \\
InSb & $\mathrm{CMP}+\mathrm{CDP}$ & $\left(\mathrm{NH}_{4}\right)_{2} \mathrm{Cr}_{2} \mathrm{O}_{7}-\mathrm{HBr}-\mathrm{EG}$ & 0.3 \\
\hline
\end{tabular}

it needs to note that CDP cleaning can produce the similar result of surface state after the larger thickness removal.

EDX measurements show that the treatment of wafers in polishing compositions produces surface chemistries with the stoichiometric ratio of $[\mathrm{In}] /[\mathrm{Sb}]$ as shown in Table 2 .

Obtained results confirm that semiconductor/polishing solution interaction produces uniform etching of both elements. InSb surface, obtained after dissolution process in the unpolishing composition, is reached by In and contains the slight amount of $\mathrm{C}, \mathrm{N}$ and $\mathrm{O}$ elements.

Raman scattering measurements of the InAs, InSb and GaAs, GaSb surfaces were carried out after cutting CMP and CDP process (Fig. 3).

After CDP and CMP polishing, changes in line position have similar tendency. The decrease in the related intensity of TO (InAs) peaks of the polished substrate, which is in accordance with the local structural defects, confirms that both cleaning treatments produce the remove of damaged layers to more structured surface quality.

The GaAs crystal has the best quality of untreated crystal state. Chemical preparation of the gallium arsenide wafer produces the increase in the intensity and the drop of half-width of the allowed in the experiment geometry TO (GaAs) peak. Furthermore, the wet etching has the maximum result in the surface modification, in comparison with other semiconductors.
Fig. 1 Micrographs of the surface of InSb crystal after CDP treatment a polishing solution $\left(\mathrm{NH}_{4}\right)_{2} \mathrm{Cr}_{2} \mathrm{O}_{7}-\mathrm{HBr}-\mathrm{EG}$ and $\mathbf{b}$ non-polishing etchant $\left(\mathrm{NH}_{4}\right)_{2} \mathrm{Cr}_{2} \mathrm{O}_{7}-\mathrm{HBr}$

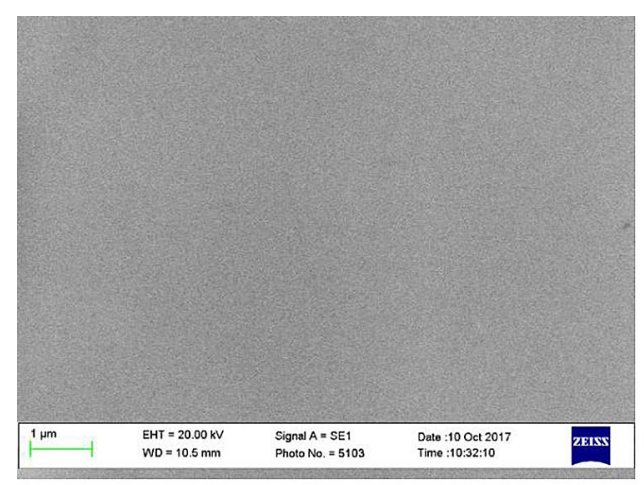

a

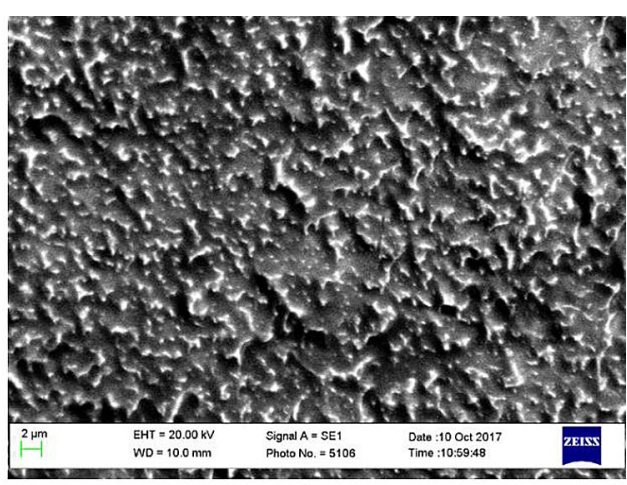

b 


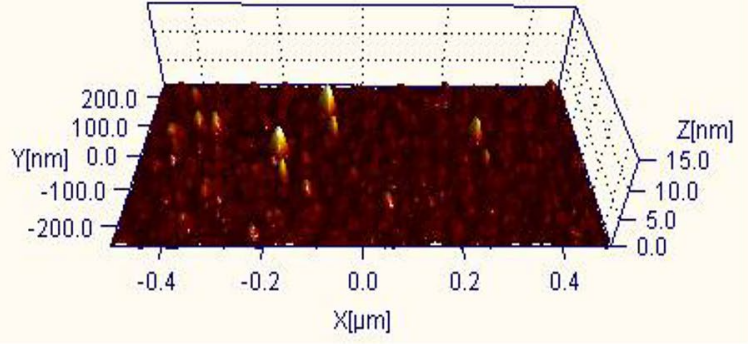

$\mathbf{a}$

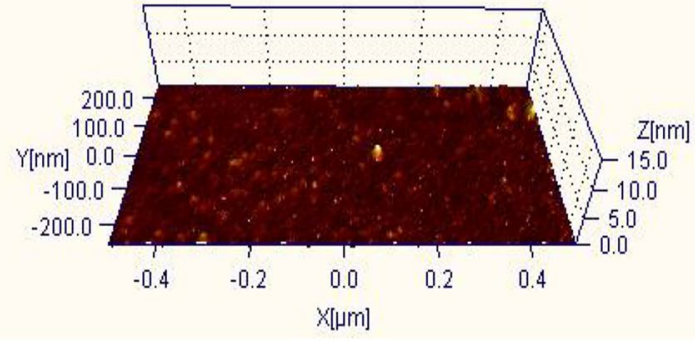

$\mathbf{b}$

Fig. 2 AFM images of InAs crystal surface taken after CDP (a) and CMP (b) treatment in the $\left(\mathrm{NH}_{4}\right)_{2} \mathrm{Cr}_{2} \mathrm{O}_{7}-\mathrm{HBr}-\mathrm{EG}$ etchant

Table 2 Elemental composition of the surface of InSb crystals after CDP process by the X-ray microscopy

Fig. 3 Raman spectra of InAs, InSb, GaAs and GaSb surface before (green line) and after CMP (red line) and CDP (black line) with $\left(\mathrm{NH}_{4}\right)_{2} \mathrm{Cr}_{2} \mathrm{O}_{7}-\mathrm{HBr}-$ $\mathrm{CH}_{2}(\mathrm{OH}) \mathrm{CH}_{2}(\mathrm{OH})$ solution

\begin{tabular}{lllllll}
\hline Etchant composition & Surface condition & \multicolumn{4}{l}{ Concentrations of elements (wt.\%) } \\
\cline { 3 - 6 } & & $\mathrm{In}$ & $\mathrm{Sb}$ & $\mathrm{C}$ & $\mathrm{N}$ & $\mathrm{O}$ \\
\hline$\left(\mathrm{NH}_{4}\right)_{2} \mathrm{Cr}_{2} \mathrm{O}_{7}-\mathrm{HBr}-\mathrm{EG}$ & Mirror-like surface & 48.6 & 51.4 & 0.0 & 0.0 & 0.0 \\
$\left(\mathrm{NH}_{4}\right)_{2} \mathrm{Cr}_{2} \mathrm{O}_{7}-\mathrm{HBr}$ & White translucent film & 46.7 & 48.0 & 2.4 & 1.2 & 1.7 \\
\hline
\end{tabular}

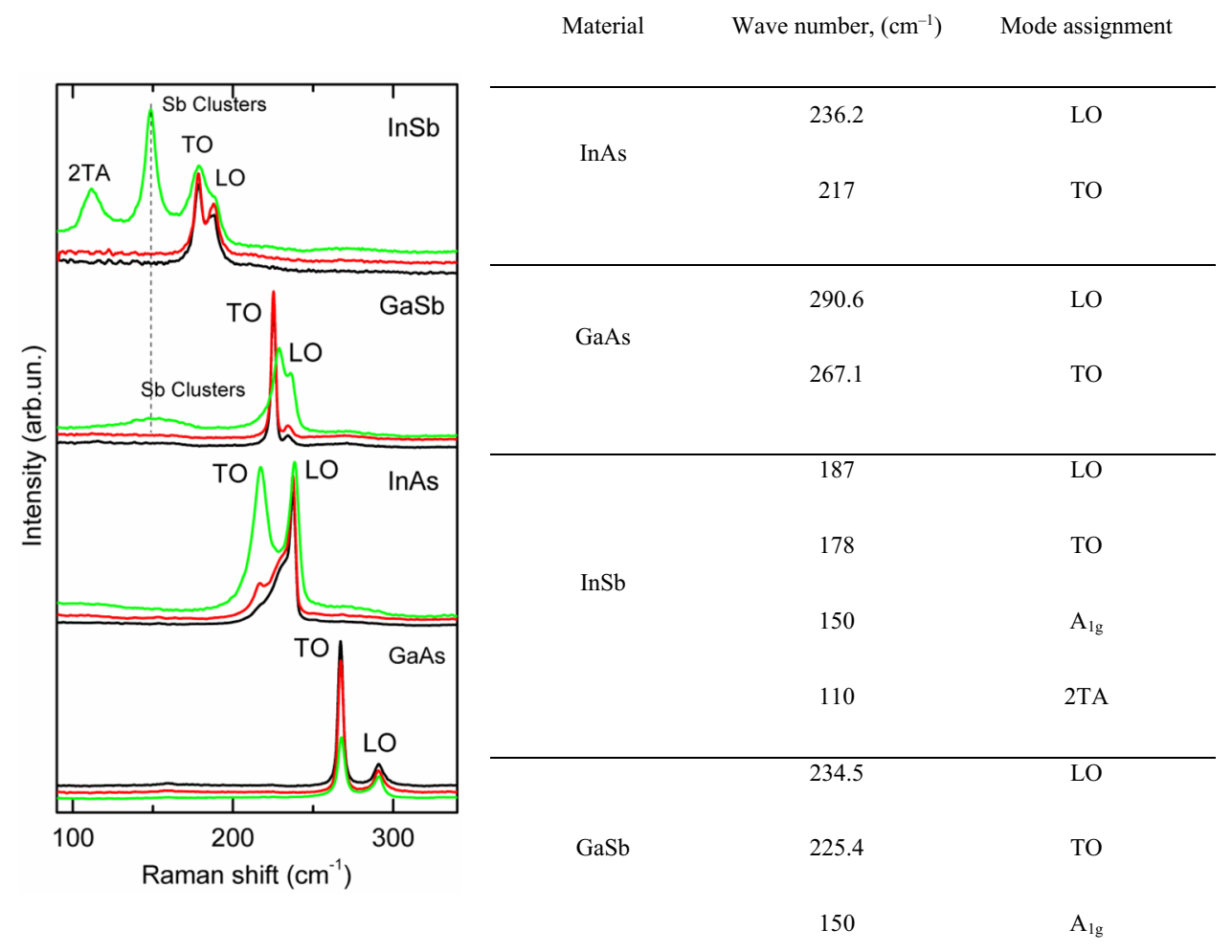

Chemical dissolution of InSb wafers led to the disappearance of the registered $\mathrm{A}_{1 \mathrm{~g}}$ phonon, which corresponds to the elemental $\mathrm{Sb}$ and $\mathrm{Sb}-\mathrm{Sb}$ bond vibration, and $2 \mathrm{TA}$ mode of second-order Raman processes (Zhou et al. 2011; Carles et al. 1984). Wet etching by CDP and CMP has the least limitation on the surface quality state of the indium antimonide, in relation to other substrates.

$\mathrm{GaSb}$ wafers are more sensitive to the wet etching than InSb crystals. This tendency may be related to properties of the crystal lattice. The dissolution process 


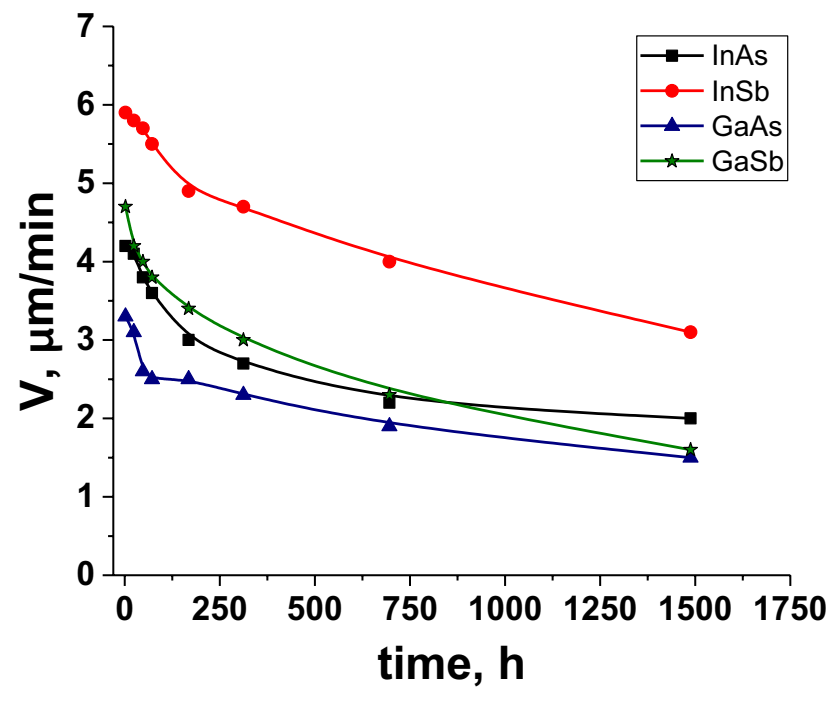

Fig. 4 Etching rate dependency on the $\left(\mathrm{NH}_{4}\right)_{2} \mathrm{Cr}_{2} \mathrm{O}_{7}-\mathrm{HBr}-\mathrm{EG}$ retention time

of the semiconductor in $\left(\mathrm{NH}_{4}\right)_{2} \mathrm{Cr}_{2} \mathrm{O}_{7}-\mathrm{HBr}-\mathrm{EG}$ etchant promotes the significant increase in the intensity of $\mathrm{TO}(\mathrm{GaSb})$ and disappearance of $\mathrm{Sb}-\mathrm{Sb}$ bond vibration. Treated wafers have more amorphous surface state that could corresponds to the better adsorption of $\mathrm{Sb}$.

Raman measurements show the reduction in the intensity of forbidden modes (in the back-scattering geometry) and increase in the allowed phonons intensity after nanoscale CDP and CMP treatments. The obtained results suggest the improvement of the surface state.

We have expounded that the solution ageing has no significant effect on the features of the semiconductor CDP. The increase in the retention time of etchant leads to the slight reduction in etching rate.

The intensity of dissolution speed decline rises in the following way: $3.3-1.5 \mu \mathrm{m} / \mathrm{min}(\mathrm{GaAs}) \rightarrow 4.2-2.1 \mu \mathrm{m} /$ $\min (\mathrm{InAs}) \rightarrow 5.9-3.2 \mu \mathrm{m} / \mathrm{min}(\mathrm{InSb}) \rightarrow 4.7-1.65 \mu \mathrm{m} / \mathrm{min}$ (GaSb) (Fig. 4). We suppose that such tendency may be caused by losing the free $\mathrm{Br}_{2}$ that forms in the etching solution. However, it does not determine the quality of polished crystals. Bromine-emerging compositions, based on $\left(\mathrm{NH}_{4}\right)_{2} \mathrm{Cr}_{2} \mathrm{O}_{7}$, are applicable for long-term utilizing and getting of polished surface.

\section{Conclusions}

To summarize, we have investigated and compared the influence of nanoscale CDP and CMP procedure on features of the III-V semiconductor dissolution in the $\left(\mathrm{NH}_{4}\right)_{2} \mathrm{Cr}_{2} \mathrm{O}_{7}-\mathrm{HBr}-\mathrm{CH}_{2}(\mathrm{OH}) \mathrm{CH}_{2}(\mathrm{OH})$ etching solutions. Bromine-emerging etchant, based on $\left(\mathrm{NH}_{4}\right)_{2} \mathrm{Cr}_{2} \mathrm{O}_{7}$, is characterized by the low dissolution rate of InAs, GaAs, InSb and $\mathrm{GaSb}$ substrates $(0.1-57 \mu \mathrm{m} / \mathrm{min})$. The impact of solvent concentration on the etching rate has linear dependence. The mechanical effect of CMP procedure provides the increase in dissolution rate, in comparison with CDP treatment. The interaction between substrates and etchant components is followed by formation of polished (in the polishing etchant composition) and passivated (in the case of CDP in solution with maximum of the oxidant concentration) surfaces with roughness less than $1 \mathrm{~nm}$. The passivation effect of solutions was found to be dependent on the reagent concentrations. According to Raman measurements, the both treatment produces decrease in the damaged structure of the surface to layers with the more ordered state.

Acknowledgements Part of current project was supported by the National Academy of Science of Ukraine (Grant III-08-16).

\section{Declarations}

Conflict of interest On behalf of all authors, the corresponding author states that there is no conflict of interest.

Open Access This article is licensed under a Creative Commons Attribution 4.0 International License, which permits use, sharing, adaptation, distribution and reproduction in any medium or format, as long as you give appropriate credit to the original author(s) and the source, provide a link to the Creative Commons licence, and indicate if changes were made. The images or other third party material in this article are included in the article's Creative Commons licence, unless indicated otherwise in a credit line to the material. If material is not included in the article's Creative Commons licence and your intended use is not permitted by statutory regulation or exceeds the permitted use, you will need to obtain permission directly from the copyright holder. To view a copy of this licence, visit http://creativecommons.org/licenses/by/4.0/.

\section{References}

Arimanwa JI, Onwuka DO, Arimanwa MC, Ajoku CA (2019) Simplex lattice design models for the determination of modulus of rupture of concretes. Niger J Technol Dev 16(4):213. https://doi.org/10. 4314/njtd.v16i4.8

Bennett BR, Magno R, Boos JB, Kruppa W, Ancona MG (2005) Antimonide-based compound semiconductors for electronic devices: a review. Solid-State Electron 49(12):1875-1895. https://doi.org/ 10.1016/j.sse.2005.09.008

Carles R, Renuccl JB, Gheorghiu A, Theye M-L (1984) Raman studies of non-stoichiometric amorphous GaSb films. Philos Mag B 49(1):63-71. https://doi.org/10.1080/13642818408246500

Cornell JA (1986) A comparison between two ten-point designs for studying three-component mixture systems. J Qual Technol 18(1):1-15. https://doi.org/10.1080/00224065.1986.11978980

Hong-Yue H, Wei X, Guo-Wei W, Ying-Qiang X, Zheng-Wei R, Xi $\mathrm{H}$, Zhen-Hong H, Yong-Ping L, Si-Hang W, Zhi-Chuan N (2015) Wet chemical etching of antimonide-based infrared materials. Chin Phys Lett 32(10):107302(1-4). https://doi.org/10.1088/ 0256-307X/32/10/107302 
Hospodkova A, Hulicius E, Pangrac J, Dominiec F, Mikhailova MP, Veinger AI, Kochman IV (2017) InAs/GaSb/AlSb composite quantum well structure preparation with help of reflectance anisotropy spectroscopy. J Crys Growth 464:206-210. https://doi. org/10.1016/j.jcrysgro.2016.11.079

Kimukin I, Biyikli N, Ozbay E (2003) InSb high-speed photodetectors grown on GaAs substrate. J Appl Phys 94(8):5414-5416. https:// doi.org/10.1063/1.1611286

Kowalewski A, Martyniuk P, Markowska O, Benyahia D, Gawron W (2016) New wet etching solution molar ratio for processing T2SLs InAs/GaSb nBn MWIR infrared detectors grown on GaSb substrates. Mater Sci Semicond Proc 41:261-264. https://doi.org/10. 1016/j.mssp.2015.08.034

Kuźmicz A, Chmielewski K, Serebrennikova O, Muszalski J (2017) Selective etching of GaAs grown over AlAs etch-stop layer in buffered citric acid $/ \mathrm{H}_{2} \mathrm{O}_{2}$ solution. Mater Sci Semicond Proc 63:52-57. https://doi.org/10.1016/j.mssp.2017.01.020

Levchenko IV, Stratiychuk IB, Tomashyk VN, Malanych GP (2017a) Chemical interaction of InAs, InSb, GaAs, and GaSb with $\left(\mathrm{NH}_{4}\right)_{2} \mathrm{Cr}_{2} \mathrm{O}_{7}-\mathrm{HBr}-\mathrm{C}_{4} \mathrm{H}_{6} \mathrm{O}_{6}$ etching solutions. Inorg Mater 53(9):896-901. https://doi.org/10.1134/S0020168517080118

Levchenko IV, Stratiychuk IB, Tomashyk VM, Malanych GP, Korchovyi AA (2017b) Features of the chemical polishing of InAs, GaAs, InSb and $\mathrm{GaSb}$ crystals in the $\left(\mathrm{NH}_{4}\right)_{2} \mathrm{Cr}_{2} \mathrm{O}_{7}-\mathrm{HBr}-\mathrm{CH}_{2}(\mathrm{OH})$ $\mathrm{CH}_{2}(\mathrm{OH})$ solutions. Issues Chem Chem Technol 2(111):29-35

Levchenko I, Tomashyk V, Stratiychuk I, Malanych G, Korchovyi A, Kryvyi S, Kolomys A (2018) Formation of the InAs, InSb GaAs and GaS-polished surface. Appl Nanosci 8(5):949-953. https:// doi.org/10.1007/s13204-018-0788-7

Masuda T, Sekine K, Nagase K, Wickramasinghe KS, Mishima TD, Santos MB, Hirayama Y (2018) Transport characteristics of InSb trench-type in-plane gate quantum point contact. Appl Phys Lett 112:192103(1-5). https://doi.org/10.1063/1.5023836

$\mathrm{Na}$ J, Lee S, Lim S (2017) Oxidation and etching behaviors of the InAs surface in various acidic and basic chemical solutions. Surf Sci 658:22-30. https://doi.org/10.1016/j.susc.2017.01.002

Perevoshchikov VA (1995) Processy khimiko-dinamicheskogo polirovaniya povierkhnosti poluprovodnikov. Vysokochist Veshchestva $2: 5-29$
Qiu H, Hu C, Peng C, Qiao K, Guo X, Liu X (2016) Study on flawed surface of GaAs epitaxial wafer in the process of wet chemical etching. Proc SPIE 10255:102554Y(1-10). https://doi.org/10. $1117 / 12.2268546$

Renteria EJ, Muniz AJ, Addamane SJ, Shima DM, Hains CP, Balakrishnan $\mathrm{G}$ (2015) Isolating GaSb membranes grown metamorphically on GaAs substrates using highly selective substrate removal etch processes. J Electron Mater 44(5):1327-1331. https://doi.org/10.1007/s11664-015-3625-8

Seo D, Na J, Lee S, Lim S (2017) Behavior of GaSb (100) and InSb (100) surfaces in the presence of $\mathrm{H}_{2} \mathrm{O}_{2}$ in acidic and basic cleaning solutions. Appl Surf Sci 399:523-534. https://doi.org/10.1016/j. apsusc.2016.12.114

Seong T-Y, Amano H (2020) Surface passivation of light emitting diodes: from nano-size to conventional mesa-etched devices. Surf Interfaces 21:100765m(1-15). https://doi.org/10.1016/j. surfn.2020.100765

Tripathy SK, Pattanaik A (2016) Optical and electronic properties of some binary semiconductors from energy gaps. Opt Mater 53:123-133. https://doi.org/10.1016/j.optmat.2016.01.012

Vanýsek P (2020) Electrochemical series. http://www2.chm.ulaval.ca/ gecha/chm2903/7_equilibres_electrochimiques/potentiels_reduc tion_CRC.pdf. Accessed 26 Dec 2020

Xie Z (2005) Microdisk cavity integration with InAs quantum dots: from as-grown to regrowth. PhD dissertation. Thesis, Stanford University

You M, Sun Q, Li S, Yin L, Li X, Liu J (2017) Study on HCl system wet-etching process of GaSb-based materials. Adv Comp Sci Res 71:90-93. https://doi.org/10.2991/icmmita-16.2016.18

Zhou X, Guo W, Perez-Bergquist AG, Wei Q, Chen Y, Sun K, Wang L (2011) Optical properties of GaSb nanofibers. Nanoscale Res Lett 6(6):1-6. https://doi.org/10.1007/s11671-010-9739-2

Publisher's Note Springer Nature remains neutral with regard to jurisdictional claims in published maps and institutional affiliations. 